\title{
Exercise capacity as an independent risk factor for adverse cardiovascular outcomes among nondiabetic and diabetic patients
}

Bredy Pierre-Louis ${ }^{1}$, Achuta K. Guddati ${ }^{2}$, Muhammed Khyzar Hayat Syed ${ }^{1}$, Vanessa E. Gorospe ${ }^{1}$, Mark Manguerra', Chaitali Bagchi' ${ }^{1}$, Wilbert S. Aronow ${ }^{3}$, Chul Ahn ${ }^{4}$ 1Department of Medicine, Columbia University Medical Center Harlem Hospital
Center, New York, USA
2Massachusetts General Hospital Harvard Medical School, Boston, USA
${ }^{3}$ Westchester Medical Center/New York Medical College, Valhalla, New York, USA
${ }^{4}$ Department of Clinical Sciences, University of Texas Southwestern Medical School,
Dallas, USA

Submitted: 3 March 2013

Accepted: 31 March 2013

Arch Med Sci 2014; 10, 1: 25-32

DOI: $10.5114 /$ aoms.2014.40731

Copyright @ 2014 Termedia \& Banach

\section{Abstract}

Introduction: To investigate if decreased exercise capacity is an independent risk factor for major adverse cardiovascular events (MACE) in diabetics and nondiabetics.

Material and methods: The association of decreased exercise capacity (EC) during a treadmill exercise sestamibi stress test with MACE was investigated in 490 nondiabetics and 404 diabetics. Mean follow-up was 53 months.

Results: Nondiabetics with a predicted EC $<85 \%$ had a higher prevalence of myocardial ischemia (34\% vs. $19 \%, p=0.0002)$, 2 - or 3 -vessel obstructive coronary artery disease (CAD) ( $31 \%$ vs. $13 \%, p=0.016)$, myocardial infarction (MI) $(17 \%$ vs. $7 \%, p=0.0005)$, stroke ( $8 \%$ vs. $2 \%, p=0.002)$, death $(11 \%$ vs. $3 \%$, $p=0.0002)$, and $\mathrm{MI}$ or stroke or death at follow-up (32\% vs. $11 \%, p<0.001)$ compared to nondiabetics with a predicted EC $\geq 85 \%$. Diabetics with a predicted EC $<85 \%$ had a higher prevalence of myocardial ischemia ( $48 \%$ vs. $32 \%$, $p=0.0009), 2$ - or 3 -vessel obstructive CAD (54\% vs. $28 \%, p=0.001)$, MI ( $32 \%$ vs. $14 \%, p<0.001)$, stroke ( $22 \%$ vs. $6 \%, p<0.001)$, death $(17 \%$ vs. $9 \%$, $p=0.031)$, and MI or stroke or death at follow-up ( $65 \%$ vs. $27 \%, p<0.001)$. Stepwise Cox regression analysis showed decreased EC was an independent and significant risk factor for MACE among nondiabetics (hazard ratio 3.3, $p<0.0001$ ) and diabetics (hazard ratio 2.7, $p<0.0001$ ).

Conclusions: Diabetics and nondiabetics with decreased EC were at increased risk for MACE with nondiabetics and decreased EC at similar risk as diabetics with normal EC.

Key words: exercise capacity, major adverse cardiac events, diabetes.

\section{Introduction}

A decreased exercise capacity (EC) has been associated with an increased risk of all-cause mortality and major adverse cardiovascular events (MACE) [1-6]. The mechanism by which reduced EC increases mortality and MACE is unknown, but may be linked to increased inflammation and concomitant endothelial dysfunction leading to accelerated

\author{
Corresponding author: \\ Wilbert S. Aronow MD, FACC, \\ FAHA \\ Cardiology Division \\ Westchester Medical Center \\ New York Medical College \\ Macy Pavilion, Room 138 \\ Valhalla, NY 10595 USA \\ Phone: 9144935311 \\ Fax: 9142356274 \\ E-mail: wsaronow@aol.com
}


atherosclerotic disease [7-9]. Patients with decreased EC as demonstrated on a treadmill stress test have been shown to have a higher incidence of MACE, including myocardial infarction, stroke, and death, compared to those with normal EC [10]. These findings have been consistent among patients of different ethnicities, men and women, nondiabetics and diabetics, and patients with left ventricular hypertrophy $[10,11]$. Multivessel coronary artery disease (CAD) is also associated with increased cardiovascular events [12].

We performed a study in 490 nondiabetics and 404 diabetics with no history of CAD to further investigate the association of decreased EC during an exercise treadmill sestamibi stress test (TESST) with the prevalence of myocardial ischemia; the prevalence of 2- or 3-vessel obstructive $C A D$, and the incidence of myocardial infarction, stroke, death, and myocardial infarction or stroke or death. Coronary artery disease was diagnosed as previously described [13-21].

\section{Material and methods}

A TESST was performed as previously described [22] in 490 nondiabetics and 404 type 2 diabetics who were consecutive unselected patients with no history of CAD, peripheral vascular disease, diabetic neuropathy, chronic obstructive pulmonary disease, or other pulmonary disease that could possibly limit EC. These patients were referred for a TESST by a primary care physician or cardiologist because of chest pain or dyspnea (anginal symptoms) from 2005 to 2009. Diabetic patients were evaluated separately because diabetes is a recognized CAD equivalent and, therefore, these patients have a higher morbidity and mortality at baseline [23]. The patients were predominantly African-American and Latino from an urban population.

All TESSTs were symptom-limited. Peak EC was measured as the percentage of maximal age- and sex-predicted metabolic equivalents (METs). The maximal predicted EC (100\% predicted-METS) for each patient was calculated using previously validated models of functional capacity for women [2] and for men [24]. Achieved METs were determined from the final speed and grade of the treadmill. The percentage of maximal predicted EC achieved by each patient was calculated by dividing the METs achieved during exercise stress testing by the $100 \%$ predicted METs based on age and gender. An achieved EC $<85 \%$ of predicted age- and gender-adjusted EC is associated with increased mortality [1-3] and was considered to be decreased. Nondiabetic patients with a decreased EC were compared regarding the prevalence of myocardial ischemia and 2- or 3-vessel obstructive $C A D$ and the incidence of myocardial infarction, stroke, or death during follow-up to nondiabetic patients with normal EC ( $\geq 85 \%$ predicted METS). The same comparisons were analyzed for diabetic patients.

Two board-certified nuclear cardiologists reviewed the TESSTs for myocardial ischemia. Of the 490 non-diabetic patients, 121 (25\%) and 158 of the 404 diabetic patients (39\%) underwent coronary angiography because the TESST showed evidence of myocardial ischemia. The coronary angiograms were interpreted by 2 board-certified interventional cardiologists for the presence of obstructive CAD. Obstructive CAD was diagnosed if there was $>50 \%$ narrowing of at least 1 major coronary artery. The patients were followed for the incidence of myocardial infarction or stroke or death. Mean follow-up was 53 months.

\section{Statistical analysis}

Student's $t$ tests were performed to compare continuous variables between nondiabetic patients with decreased and normal EC and similarly for the diabetic patients. The $\chi^{2}$ tests and Fisher's exact tests were used to compare dichotomous variables between the respective groups. Stepwise Cox regression analysis was performed to identify significant independent prognostic risk factors for the time to myocardial infarction or stroke or death using the variables enumerated in the baseline characteristic tables. The Institutional Review Board of Columbia University Medical Center approved this study.

\section{Results}

All patients stopped exercise because of dyspnea. No studies were terminated because of deconditioning, arrhythmias, intermittent claudication, or symptoms other than dyspnea.

Of 490 nondiabetic patients, 297 (61\%) had a predicted EC $\geq 85 \%$ and 193 (39\%) had a predicted EC $<85 \%$. Table I shows the baseline characteristics of nondiabetic patients with normal EC compared to those with decreased EC. No significant differences were found between the 2 groups. Table II shows the prevalence of myocardial ischemia, obstructive CAD, multivessel CAD, and the incidence of myocardial infarction, stroke, death, and myocardial infarction or stroke or death in nondiabetic patients with normal EC compared to those with decreased EC. Table II also lists levels of statistical significance. Table III shows the stepwise Cox regression analysis for the time to the development of myocardial infarction or stroke or death. A predicted EC $<85 \%$ was a significant independent predictor for the time to the development of myocardial infarction or stroke or death. Nondiabetic patients with decreased EC had a ha- 
Table I. Baseline characteristics of nondiabetics with exercise capacity $\geq 85 \%$ vs. nondiabetics with exercise capacity $<85 \%$

\begin{tabular}{|c|c|c|c|}
\hline Clinical characteristics & $\begin{array}{c}\text { Nondiabetics } \\
\text { EC } \geq 85 \%(n=297)\end{array}$ & $\begin{array}{c}\text { Nondiabetics } \\
\text { EC }<85 \%(n=193)\end{array}$ & Value of $p$ \\
\hline Age [years] & $67.0 \pm 10.5$ & $67.0 \pm 10.3$ & NS \\
\hline Gender & & & NS \\
\hline Male & $154(52 \%)$ & $102(53 \%)$ & \\
\hline Female & $143(48 \%)$ & $91(47 \%)$ & \\
\hline Ethnicity & & & NS \\
\hline African-American & $229(77 \%)$ & $156(81 \%)$ & \\
\hline Latino & 50 (17\%) & 29 (15\%) & \\
\hline White & $8(3 \%)$ & $4(2 \%)$ & \\
\hline Asian & $10(3 \%)$ & $4(2 \%)$ & \\
\hline $\mathrm{BMI}>30 \mathrm{~kg} / \mathrm{m}^{2}$ & 92 (31\%) & $64(33 \%)$ & NS \\
\hline Hypertension & $240(81 \%)$ & $160(83 \%)$ & NS \\
\hline Dyslipidemia & $214(72 \%)$ & $147(76 \%)$ & NS \\
\hline Smoking & 40 (13\%) & $23(12 \%)$ & NS \\
\hline $\mathrm{GFR} \geq 60 \mathrm{ml} / \mathrm{min} / 1.73 \mathrm{~m}^{2}$ & $220(74 \%)$ & $139(72 \%)$ & NS \\
\hline GFR $30-59 \mathrm{ml} / \mathrm{min} / 1.73 \mathrm{~m}^{2}$ & $65(22 \%)$ & $44(23 \%)$ & NS \\
\hline $\mathrm{GFR} \leq 30 \mathrm{ml} / \mathrm{min} / 1.73 \mathrm{~m}^{2}$ & $12(4 \%)$ & $10(5 \%)$ & NS \\
\hline Aspirin & 270 (91\%) & $172(89 \%)$ & NS \\
\hline Statins & $205(69 \%)$ & $139(72 \%)$ & NS \\
\hline$\beta$-Blockers & $140(47 \%)$ & $83(43 \%)$ & NS \\
\hline ACE inhibitors/ARBs & $211(71 \%)$ & $143(74 \%)$ & NS \\
\hline Follow-up [months] & $55.7 \pm 19.0$ & $53.6 \pm 18.6$ & NS \\
\hline
\end{tabular}

EC - exercise capacity, BMI - body mass index, GFR - glomerular filtration rate, ACE - angiotensin- converting enzyme, ARB - angiotensin receptor blocker, NS - not significant

Table II. Prevalence of myocardial ischemia, obstructive coronary artery disease, and multivessel coronary artery disease, and incidence of myocardial infarction, stroke, death and myocardial infarction or stroke or death in nondiabetics with exercise capacity $\geq 85 \%$ vs. nondiabetics with exercise capacity $<85 \%$

\begin{tabular}{|lccc|}
\hline Clinical characteristics & $\begin{array}{c}\text { Nondiabetics } \\
\mathrm{EC} \geq 85 \%(n=297)\end{array}$ & $\begin{array}{c}\text { Nondiabetics } \\
\mathrm{EC}<85 \%(n=193)\end{array}$ & Value of $p$ \\
\hline Myocardial ischemia & $56(19 \%)$ & $65(34 \%)$ & 0.0002 \\
\hline Normal coronary arteries & $29 / 56(52 \%)$ & $13 / 65(20 \%)$ & 0.0003 \\
\hline Non-obstructive CAD & $12 / 56(21 \%)$ & $11 / 65(17 \%)$ & NS \\
\hline 1-vessel obstructive CAD & $8 / 56(14 \%)$ & $21 / 65(32 \%)$ & 0.021 \\
\hline 2-vessel obstructive CAD & $4 / 56(7 \%)$ & $11 / 65(17 \%)$ & NS \\
\hline 3-vessel obstructive CAD & $3 / 56(5 \%)$ & $9 / 65(14 \%)$ & NS \\
\hline 2- or 3-vessel obstructive CAD & $7 / 56(13 \%)$ & $20 / 65(31 \%)$ & 0.016 \\
\hline Myocardial infarction & $21(7 \%)$ & $33(17 \%)$ & 0.0005 \\
\hline Stroke & $6(2 \%)$ & $15(8 \%)$ & 0.002 \\
\hline Death & $9(3 \%)$ & $22(11 \%)$ & 0.0002 \\
\hline Ml or stroke or death & $33(11 \%)$ & $61(32 \%)$ & $<0.0001$ \\
\hline
\end{tabular}

$C A D$ - coronary artery disease, $M I$ - myocardial infarction, EC - exercise capacity, NS - not significant 
Table III. Stepwise Cox regression analysis for the time to the development of myocardial infarction, stroke, or death among nondiabetics with exercise capacity $\geq 85 \%$ vs. nondiabetics with exercise capacity $<85 \%$

\begin{tabular}{|c|c|c|c|c|}
\hline Outcome & Variable & $\begin{array}{l}\text { Parameter estimate } \\
\qquad( \pm \text { STD })\end{array}$ & $\begin{array}{l}\text { Hazard ratio } \\
\quad(95 \% \mathrm{Cl})\end{array}$ & Value of $p$ \\
\hline $\begin{array}{l}\text { MI, stroke, or } \\
\text { death }\end{array}$ & $\begin{array}{l}\text { Exercise capacity }<85 \% \text { of predicted } \\
\text { metabolic equivalents achieved }\end{array}$ & $1.20 \pm 0.22$ & $3.3(2.2-5.1)$ & $<0.0001$ \\
\hline
\end{tabular}

MI- myocardial infarction

Table IV. Baseline characteristics of diabetics with exercise capacity $\geq 85 \%$ vs. diabetics with exercise capacity $<85 \%$

\begin{tabular}{|c|c|c|c|}
\hline Clinical characteristics & $\begin{array}{c}\text { Diabetics } \\
\mathrm{EC} \geq 85 \%(n=223)\end{array}$ & $\begin{array}{c}\text { Diabetics } \\
\text { EC }<85 \%(n=181)\end{array}$ & Value of $p$ \\
\hline Age [years] & $67.7 \pm 10.4$ & $67.0 \pm 10.4$ & NS \\
\hline Gender & & & NS \\
\hline Male & 109 (49\%) & $88(49 \%)$ & \\
\hline Female & $114(51 \%)$ & $93(51 \%)$ & \\
\hline Ethnicity & & & NS \\
\hline African-American & $165(74 \%)$ & $139(77 \%)$ & \\
\hline Latino & $44(20 \%)$ & $33(18 \%)$ & \\
\hline White & $6(3 \%)$ & $4(2 \%)$ & \\
\hline Asian & $8(4 \%)$ & $5(3 \%)$ & \\
\hline $\mathrm{BMI}>30 \mathrm{~kg} / \mathrm{m}^{2}$ & $76(34 \%)$ & $65(36 \%)$ & NS \\
\hline Hypertension & $212(95 \%)$ & $170(94 \%)$ & NS \\
\hline Dyslipidemia & $214(96 \%)$ & $176(97 \%)$ & NS \\
\hline Smoking & $40(18 \%)$ & $32(18 \%)$ & NS \\
\hline $\mathrm{GFR} \geq 60 \mathrm{ml} / \mathrm{min} / 1.73 \mathrm{~m}^{2}$ & $125(56 \%)$ & 99 (55\%) & NS \\
\hline GFR $30-59 \mathrm{ml} / \mathrm{min} / 1.73 \mathrm{~m}^{2}$ & $74(33 \%)$ & $63(35 \%)$ & NS \\
\hline $\mathrm{GFR} \leq 30 \mathrm{ml} / \mathrm{min} / 1.73 \mathrm{~m}^{2}$ & $24(11 \%)$ & $19(10 \%)$ & NS \\
\hline Aspirin & $212(95 \%)$ & $174(96 \%)$ & NS \\
\hline Statins & 207 (93\%) & $172(95 \%)$ & NS \\
\hline$\beta$-Blockers & $198(89 \%)$ & 165 (91\%) & NS \\
\hline ACE inhibitors/ARBs & $214(96 \%)$ & $176(97 \%)$ & NS \\
\hline Insulin & 87 (39\%) & $74(41 \%)$ & NS \\
\hline Follow-up [months] & $50.4 \pm 18.6$ & $50.9 \pm 16.2$ & NS \\
\hline
\end{tabular}

$E C$ - exercise capacity, BMI - body mass index, GFR - glomerular filtration rate, $A C E$ - angiotensin- converting enzyme, ARB - angiotensin receptor blocker, NS - not significant

zard ratio of $3.3(p<0.0001)$ for the incidence of myocardial infarction or stroke or death during the follow-up period. Hypertension, dyslipidemia and smoking were also independent risk factors for MACE as has been previously demonstrated in other studies [25-27].

Of the 404 diabetic patients, 223 (55\%) had a predicted $\mathrm{EC} \geq 85 \%$ and 181 (45\%) had a predicted $\mathrm{EC}<85 \%$. Table IV shows the baseline characteristics of diabetic patients with normal EC compared to those with decreased EC. No significant differences were found between the 2 groups. Table $\checkmark$ shows the prevalence of myocardial ischemia, obstructive CAD, multivessel CAD, and the incidence of myocardial infarction, stroke, death, and myocardial infarction or stroke or death in diabetic patients with normal EC compared to those with decreased EC. Table $V$ also lists levels of statistical significance. Table VI shows the stepwise Cox regression analysis for the time to the development of myocardial infarction or stroke or death. A predicted EC $<85 \%$ was a significant independent predictor for the time to the development of myocardial infarction or stroke or death. Diabetic 
Table V. Prevalence of myocardial ischemia, obstructive coronary artery disease, and multivessel coronary artery disease, and incidence of myocardial Infarction, stroke, death and myocardial infarction or stroke or death in diabetics with exercise capacity $\geq 85 \%$ vs. diabetics with exercise capacity $<85 \%$

\begin{tabular}{|c|c|c|c|}
\hline Clinical characteristics & $\begin{array}{c}\text { Diabetics } \\
\text { EC } \geq 85 \%(n=223)\end{array}$ & $\begin{array}{c}\text { Diabetics } \\
\text { EC }<85 \%(n=181)\end{array}$ & Value of $p$ \\
\hline Myocardial ischemia & $71(32 \%)$ & $87(48 \%)$ & 0.0009 \\
\hline Normal coronary arteries & $20 / 71(28 \%)$ & $6 / 87(7 \%)$ & 0.0003 \\
\hline Non-obstructive CAD & $13 / 71(18 \%)$ & $8 / 87$ (9\%) & NS \\
\hline 1-vessel obstructive CAD & $18 / 71(25 \%)$ & $26 / 87(30 \%)$ & NS \\
\hline 2-vessel obstructive CAD & $11 / 71(15 \%)$ & $24 / 87(28 \%)$ & NS \\
\hline 3-vessel obstructive CAD & 9/71 (13\%) & $23 / 87(26 \%)$ & 0.032 \\
\hline 2- or 3-vessel obstructive CAD & 20/71 (28\%) & $47 / 87(54 \%)$ & 0.001 \\
\hline Myocardial infarction & $32(14 \%)$ & $58(32 \%)$ & $<0.0001$ \\
\hline Stroke & $14(6 \%)$ & $39(22 \%)$ & $<0.0001$ \\
\hline Death & $21(9 \%)$ & $30(17 \%)$ & 0.031 \\
\hline MI or stroke or death & $60(27 \%)$ & $117(65 \%)$ & $<0.0001$ \\
\hline
\end{tabular}

Table VI. Stepwise Cox regression analysis for the time to the development of myocardial infarction, stroke, or death among diabetics with exercise capacity $\geq 85 \%$ vs. diabetics with exercise capacity $<85 \%$

\begin{tabular}{|c|c|c|c|c|}
\hline Outcome & Variable & $\begin{array}{c}\text { Parameter estimate } \\
\pm \text { STD }\end{array}$ & $\begin{array}{l}\text { Hazard ratio } \\
(95 \% \mathrm{Cl})\end{array}$ & Value of $p$ \\
\hline $\begin{array}{l}\text { MI, stroke, } \\
\text { death }\end{array}$ & $\begin{array}{c}\text { Exercise capacity }<85 \% \text { of predicted } \\
\text { metabolic equivalents achieved }\end{array}$ & $0.98 \pm 0.16$ & $2.7(1.9-3.7)$ & $<0.0001$ \\
\hline
\end{tabular}

MI- myocardial infarction

patients with decreased EC had a hazard ratio of $2.7(p<0.0001)$ for the incidence of myocardial infarction or stroke or death during the follow-up period. Hypertension, dyslipidemia and smoking were also independent risk factors for MACE as has been previously demonstrated in other studies [25-27] and should be managed [28, 29].

Table VII shows the baseline characteristics of diabetic patients with normal EC compared to nondiabetic patients with decreased EC. and levels of statistical significance. Table VIII shows the prevalence of myocardial ischemia, obstructive CAD, multivessel CAD, and the incidence of myocardial infarction, stroke, death, and myocardial infarction or stroke or death in diabetic patients with normal EC compared to nondiabetic patients with decreased EC. Table VIII also lists levels of statistical significance.

\section{Discussion}

The present study provides further evidence that decreased EC as determined by METS during a TESST is a significant risk factor for MACE. In particular, this study confirms these findings in a population of primarily African-American and
Latino patients in an urban community, which few studies have previously investigated. These findings correspond to data published in previous studies and further demonstrate that the findings are consistent across different patient populations.

In a prior study of 609 diabetic patients who underwent symptom limited TESSTs for chest pain or dyspnea, patients with a predicted EC > 85\% had a $48 \%$ lower change of MI, stroke, or death at 47-month follow-up [10]. A study conducted at the Veterans Affairs Medical Center in Washington, DC involving 866 diabetic men with and without left ventricular hypertrophy who underwent an exercise stress test showed that normal EC was associated with a $43 \%$ lower mortality risk among patients with left ventricular hypertrophy and a $41 \%$ lower mortality risk among those without left ventricular hypertrophy [11]. In a study involving 6.2-year follow-up of 6213 men referred for treadmill exercise testing, researchers demonstrated that each 1-MET increase in EC conferred a $12 \%$ improvement in survival [1]. The St. James Women Take Heart Project revealed that at 8-year follow-up of 5721 asymptomatic women under- 
Table VII. Baseline characteristics of diabetics with exercise capacity $\geq 85 \%$ vs. nondiabetics with exercise capacity $<85 \%$

\begin{tabular}{|c|c|c|c|}
\hline Clinical characteristics & $\begin{array}{c}\text { Diabetics } \\
\text { EC } \geq 85 \%(n=223)\end{array}$ & $\begin{array}{c}\text { Nondiabetics } \\
\text { EC }<85 \%(n=193)\end{array}$ & Value of $p$ \\
\hline Age [years] & $67.7 \pm 10.4$ & $67 \pm 10.3$ & NS \\
\hline Gender & & & NS \\
\hline Male & 109 (49\%) & $102(53 \%)$ & \\
\hline Female & $114(51 \%)$ & $91(47 \%)$ & \\
\hline Ethnicity & & & NS \\
\hline African-American & $165(74 \%)$ & $156(81 \%)$ & \\
\hline Latino & $44(20 \%)$ & $29(15 \%)$ & \\
\hline White & $6(3 \%)$ & $4(2 \%)$ & \\
\hline Asian & $8(4 \%)$ & $4(2 \%)$ & \\
\hline $\mathrm{BMI}>30 \mathrm{~kg} / \mathrm{m}^{2}$ & $76(34 \%)$ & $64(33 \%)$ & NS \\
\hline Hypertension & $212(95 \%)$ & $160(83 \%)$ & 0.0001 \\
\hline Dyslipidemia & $214(96 \%)$ & $147(76 \%)$ & $<0.0001$ \\
\hline Smoking & $40(18 \%)$ & $23(12 \%)$ & NS \\
\hline $\mathrm{GFR} \geq 60 \mathrm{ml} / \mathrm{min} / 1.73 \mathrm{~m}^{2}$ & $125(56 \%)$ & $139(72 \%)$ & 0.0007 \\
\hline GFR $30-59 \mathrm{ml} / \mathrm{min} / 1.73 \mathrm{~m}^{2}$ & $74(33 \%)$ & $44(23 \%)$ & 0.019 \\
\hline $\mathrm{GFR} \leq 30 \mathrm{ml} / \mathrm{min} / 1.73 \mathrm{~m}^{2}$ & $24(11 \%)$ & $10(5 \%)$ & 0.038 \\
\hline Aspirin & 212 (95\%) & $172(89 \%)$ & 0.023 \\
\hline Statins & 207 (93\%) & $139(72 \%)$ & $<0.0001$ \\
\hline$\beta$-Blockers & $198(89 \%)$ & $83(43 \%)$ & $<0.0001$ \\
\hline ACE inhibitors/ARBs & $214(96 \%)$ & $143(74 \%)$ & $<0.0001$ \\
\hline Insulin & 87 (39\%) & 0 & $<0.0001$ \\
\hline Follow-up [months] & $50.4 \pm 18.6$ & $53.5 \pm 18.6$ & NS \\
\hline
\end{tabular}

receptor blocker, NS - not significant

going treadmill exercise testing, Framingham risk score-adjusted hazards ratios of death associated with MET levels of $<5,5$ to 8 , and $>8$ were 3.1 , 1.9 , and 1.0 , respectively [2].

In addition, at 8.4-year follow-up of 5721 asymptomatic women who had a treadmill exercise test, women with a predicted EC $<85 \%$ had a hazard ratio for death of 2.0 and for cardiac death of 2.4 compared with women with a predicted EC $\geq 85 \%$ [2]. In another study involving 2.7-year follow-up of 9191 patients referred for treadmill exercise testing, a predicted EC $<85 \%$ was associated with an increased risk of myocardial infarction (hazard ratio: 2.4 ), unstable angina (hazard ratio: 2.4 ), coronary revascularization (hazard ratio: 1.8 ), and death (hazard ratio: 2.9 ) compared with a predicted $\mathrm{EC}>100 \%$ [3].

At 7.5-year follow-up of 8911 white men and 6749 black men who underwent a treadmill exer- cise test, researchers demonstrated that EC was the strongest predictor of mortality and the adjusted risk of mortality was reduced by $13 \%$ for each 1-MET increase in EC [4]. A meta-analysis of 33 studies involving 102,980 persons for mortality and 84,323 persons for CAD/cardiovascular disease events showed that the relative risk of mortality and of CAD/cardiovascular disease events per 1-MET higher level of maximal aerobic capacity were 0.87 and 0.85 , respectively [5].

In a study focused on the primary prevention benefits of exercise, researchers found that of 104 patients with abnormal treadmill exercise test results with ischemic ST-segment depression achieved after exercising for $\geq 10$ METs, death occurred at 7.2-year follow-up in 1 of 104 patients (1\%) [30]. The investigators concluded that patients with ischemic ST-segment depression on a treadmill exercise test who achieved workloads 
Table VIII. Prevalence of myocardial ischemia, obstructive coronary artery disease, multivessel coronary artery disease, and incidence of myocardial infarction, stroke, death and myocardial infarction or stroke or death in diabetics with exercise capacity $\geq 85 \%$ vs. nondiabetics with exercise capacity $<85 \%$

\begin{tabular}{|c|c|c|c|}
\hline Clinical characteristics & $\begin{array}{c}\text { Diabetics } \\
\text { EC } \geq 85 \%(n=223)\end{array}$ & $\begin{array}{c}\text { Nondiabetics } \\
\text { EC }<85 \%(n=193)\end{array}$ & Value of $p$ \\
\hline Myocardial ischemia & $71(32 \%)$ & $65(34 \%)$ & NS \\
\hline Normal coronary arteries & $20 / 71(28 \%)$ & $13 / 65(20 \%)$ & NS \\
\hline Non-obstructive CAD & $13 / 71(18 \%)$ & $11 / 65(17 \%)$ & NS \\
\hline 1 -vessel obstructive CAD & $18 / 71(25 \%)$ & $21 / 65(32 \%)$ & NS \\
\hline 2-vessel obstructive CAD & $11 / 71(15 \%)$ & $11 / 65(17 \%)$ & NS \\
\hline 3-vessel obstructive CAD & $9 / 71(13 \%)$ & $9 / 65(14 \%)$ & NS \\
\hline 2- or 3-vessel obstructive CAD & $20 / 71(28 \%)$ & $20 / 65(31 \%)$ & NS \\
\hline Myocardial infarction & $32(14 \%)$ & $33(17 \%)$ & NS \\
\hline Stroke & $14(6 \%)$ & $15(8 \%)$ & NS \\
\hline Death & $21(9 \%)$ & $22(11 \%)$ & NS \\
\hline MI or stroke or death & $60(27 \%)$ & $61(32 \%)$ & NS \\
\hline
\end{tabular}

CAD - coronary artery disease, $\mathrm{MI}$ - myocardial infarction, EC - exercise capacity, NS - not significant

of $\geq 10$ METs infrequently require additional noninvasive or invasive evaluation [30].

The present study of 490 nondiabetic and 404 diabetic patients with no history of CAD who had a TESST because of chest pain or dyspnea showed that persons with a predicted EC $<85 \%$ had a higher incidence of myocardial ischemia and 2- or 3-vessel obstructive CAD. At 53-months follow-up, the incidence of myocardial infarction, stroke, or death was also significantly increased in those with a predicted EC $<85 \%$. Stepwise Cox regression analysis showed that a predicted EC $<85 \%$ was a significant independent predictor of the time to the development of myocardial infarction, stroke, or death among both nondiabetic and diabetic patients. In addition, a univariate comparison of MACE between diabetic patients with normal EC, and nondiabetic patients with decreased EC revealed no significant differences in the prevalence of myocardial ischemia and 2- or 3-vessel obstructive CAD or the incidence of myocardial infarction, stroke, or death at 53-months follow-up. These clinical findings contribute new information to the medical literature. This suggest that decreased EC may be a coronary artery disease equivalent. This finding requires further investigation in a prospective study.

The mechanism for increased mortality and cardiovascular events in patients with a reduced EC is unknown. Regular aerobic exercise has been shown to decrease vascular inflammation and improve endothelial function. Therefore, patients with decreased EC may have an accelerated atherosclerotic process [7]. This is supported by the increased prevalence of myocardial ischemia and multivessel obstructive CAD among patients with decreased EC in the study which may have caused their increased mortality and morbidity. The independent association of decreased EC and increased incidence of MACE among both nondiabetic and diabetic patients suggest that this may be a significant modifiable risk factor that should be evaluated among all patients at risk for heart disease. The patients in the current study were at increased baseline risk because of the prevalence of cardiovascular risk factors, ethnicity, socioeconomic status, and the presence of anginal symptoms prompting referral for a stress test. This study and the existing body of data indicate that EC as determined by METS during a treadmill stress test should potentially be screened among patients with risk factors for MACE. Those with decreased EC would then be considered at increased risk for MACE and should have specific interventions implemented to reduce that risk including ideally supervised exercise training and follow-up EC testing.

The patient population studied is from a single center with a high-risk cohort involving a primarily African-American and Latino population. Therefore, generalizing our findings to other populations has limitations. A long-term, prospective study of consecutive patients to investigate the significance of decreased EC as a modifiable cardiovascular risk factor among patients with existing risk factors for MACE (diabetes, hypertension, dyslipidemia and smoking), but no active anginal symptoms is currently underway at our institution. Whether increasing physical activity in patients with a decreased EC will reduce mortality 
and cardiovascular events will be investigated by this prospective trial.

\section{References}

1. Myers J, Prakash M, Froelicher V, et al. Exercise capacity and mortality among men referred for exercise testing. N Engl J Med 2002; 346: 793-801.

2. Gulati M, Pandey DK, Arnsdorf MF, et al. Exercise capacity and the risk of death in women: the St James Women Take Heart Project. Circulation 2003; 108: 1554-9.

3. Peterson PN, Magid DJ, Ross C, et al. Association of exercise capacity on treadmill with future cardiac events in patients referred for exercise testing. Arch Intern Med 2008; 168: 174-9.

4. Kokkinos P, Myers J, Kokkinos JP, et al. Exercise capacity and mortality in black and white men. Circulation 2008; 117: 614-22.

5. Kodama S, Saito K, Tanaka S, et al. Cardiorespiratory fitness as a quantitative predictor of all-cause mortality and cardiovascular events in healthy men and women: a meta-analysis. JAMA 2009; 301: 2024-35.

6. Janand-Delenne B, Savin B, Habib G, et al. Silent myocardial ischemia in patients with diabetes: who to screen. Diabetes Care 1999; 22: 1396-400.

7. Ribeiro F, Alves AJ, Duarte JA, Oliveira J. Is exercise training an effective therapy targeting endothelial dysfunction and vascular wall inflammation? Int J Cardiol 2010; 141: 214-21.

8. Luk TH, Dai YL, Siu CW, et al. Effect of exercise training on vascular endothelial function in patients with stable coronary artery disease: a randomized controlled trial. Eur J Prev Cardiol 2012; 19: 830-9.

9. Juonala M, Viikari JS, Kahonen M, et al. Life-time risk factors and progression of carotid atherosclerosis in young adults: the Cardiovascular Risk in Young Finns study. Eu Heart J 2010; 31: 1745-51.

10. Pierre-Louis B, Aronow WS, Yoon JH, et al. Incidence of myocardial infarction or stroke or death at 47-month follow-up in patients with diabetes and a predicted exercise capacity $<$ or $=85 \%$ vs $>85 \%$ during an exercise treadmill sestamibi stress test. Prev Cardiol 2010; 13: 14-7.

11. Alswat KKP, Khosla S, Kheirbek R, Nylen E. The prognostic impact of fitness on mortality in diabetics with and without left ventricular hypertrophy. Endocr Rev 2012; 33: SUN-158.

12. Muller DWM, Topol EJ, Ellis SG, et al. Multivessel coronary artery disease: a key predictor of short-term prognosis after reperfusion therapy for acute myocardial infarction. Am Heart J 1991; 121: 1042-9.

13. Lai HM, Aronow WS, Mercando AD, et al. Risk factor reduction in progression of angiographic coronary artery disease. Arch Med Sci 2012; 8: 444-8.

14. Mercando AD, Lai HM, Aronow WS, et al. Reduction in atherosclerotic events through use of aggressive risk factor reduction medications: a retrospective study in an outpatient cardiology practice. Arch Med Sci 2012; 8: 57-62.

15. Lai HM, Aronow WS, Rachdev A, et al. Incidence of mortality in 1,040 patients with coronary heart disease or hypertensive heart disease with normal and abnormal left ventricular ejection fraction and with normal and abnormal QRS duration. Arch Med Sci 2008; 4: 140-2.

16. Ramdeen N, Aronow WS, Chugh S, Asija A. Patients undergoing coronary angiography because of chest pain with hepatitis C virus have a higher prevalence of obstructive coronary artery disease than a control group. Arch Med Sci 2008; 4: 452-4.

17. Kannam H, Aronow WS, Chilappa K, et al. Association of the QRS duration on the resting electrocardiogram with the severity of coronary artery disease in 2,196 patients undergoing coronary angiography for suspected coronary artery disease. Arch Med Sci 2009; 5: 163-5.

18. Shao JH, Aronow WS, Ravipati G, et al. Prevalence of a minimal luminal cross sectional area of coronary arteries $<4 \mathrm{~mm} 2$ determined by intravascular ultrasound in patients with coronary artery calcium scores of 0-100, 100-200, 200-300, 300-400, and >400 determined by cardiac computer tomography. Arch Med Sci 2009; 5: 172-4.

19. Shen X, Aronow WS, Nair CK, et al. Thoracic aortic atheroma severity predicts high-risk coronary anatomy in patients undergoing transesophageal echocardiography. Arch Med Sci 2011; 7: 61-6.

20. Aronow WS. Osteoporosis, osteopenia, and atherosclerotic vascular disease. Arch Med Sci 2011; 7: 21-6.

21. Duncan KA, Sukhija R, Aronow WS, et al. Systolic compression of left main coronary artery by left ventricular pseudoaneurysm complicated by critical stenosis of left main coronary artery. Arch Med Sci 2012; 8: 931-3.

22. DeLuca AJ, Kaplan S, Aronow WS, et al. Comparison of prevalence of unrecognized myocardial infarction and of silent myocardial ischemia detected by a treadmill exercise sestamibi stress test in patients with versus without diabetes mellitus. Am J Cardiol 2006; 98: 1045-6.

23. Stamler J, Vaccaro O, Neaton JD, Wentworth D. Diabetes, other risk factors, and 12-yr cardiovascular mortality for men screened in the Multiple Risk Factor Intervention Trial. Diabetes Care 1993; 16: 434-44.

24. Kim ES, Ishwaran H, Blackstone E, Lauer MS. External prognostic validations and comparisons of age- and gender-adjusted exercise capacity predictions. J Am Coll Cardiol 2007; 50: 1867-75.

25. MacMahon S, Peto R, Cutler J, et al. Blood pressure, stroke, and coronary heart disease. Part 1, Prolonged differences in blood pressure: prospective observational studies corrected for the regression dilution bias. Lancet 1990; 335: 765-74.

26. Verschuren WM, Jacobs DR, Bloemberg BP, et al. Serum total cholesterol and long-term coronary heart disease mortality in different cultures. Twenty-five-year follow-up of the seven countries study. JAMA 1995; 274: 131-6.

27. The Health Benefits of Smoking Cessation: A Report of the Surgeon General. In: General USPHSOotS, ed. Bethesda: United States. Public Health Service. Office on Smoking and Health 1990.

28. Atyhyros VG, Hatzitolios Al, Karagiannis A, et al. IMproving the imPlemEntation od cuRrent guidelines for the mAnagement of major coronary hearT risk factors by multifactorial interVEntion. The IMPERATIVE renal analysis. Arch Med Sci 2011; 7: 984-92.

29. Jesic M, Silvija S, Jesic M, et al. Microalbuminuria in relation to metabolic control and blood pressure in adolescents with type 1 diabetes. Arch Med Sci 2011; 7: 1037-41.

30. Liebson PR, Amsterdam EA. Prevention of coronary heart disease. Part I. Primary prevention. Dis Mon 1999; 45: 497-571. 